\title{
The Moderating Role of Intergroup Contact in Race Composition, Perceived Similarity, and Applicant Attraction Relationships
}

\author{
Yin Lu Ng' ${ }^{1}$ Carol T. Kulik ${ }^{2}$ Prashant Bordia ${ }^{3}$
}

(C) Springer Science+Business Media New York 2015

\begin{abstract}
Purpose This study investigated the moderating effect of intergroup contact on the relationship between the race composition of organizational representatives, perceived similarity, and minority applicant attraction.

Design/Methodology/Approach 344 minority MalaysianChinese university students read a job advertisement that varied the racial composition of organizational representatives (100\% Malay or $50 \%$ Malay-50\% Chinese or $100 \%$ Chinese). Of these participants, 161 were Malaysian-Chinese in Malaysia (high intergroup contact location) and 183 were Malaysian-Chinese in Australia (low intergroup contact location). After reading the advertisement, participants responded to a series of scale items (e.g., perceived surface-level similarity, perceived deep-level similarity, and applicant attraction).

Findings Results showed that the effect of race composition on attraction was stronger for minority participants in Australia than for minority participants in Malaysia.
\end{abstract}

Yin $\mathrm{Lu} \mathrm{Ng}$

ngyl@help.edu.my

Carol T. Kulik

carol.kulik@unisa.edu.au

Prashant Bordia

prashant.bordia@anu.edu.au

1 Department of Psychology, HELP University, Level 8, Wisma HELP, Jalan Dungun, Damansara Heights, Kuala Lumpur 50490, Malaysia

2 Centre for HRM, School of Management, University of South Australia, Adelaide, SA, Australia

3 Research School of Management, College of Business \& Economics, The Australian National University, Canberra, ACT, Australia
Perceived deep-level similarity mediated this moderated relationship.

Implications The study findings suggest that organizations should include minority representatives in their recruitment advertising to attract minority applicants, particularly to attract minorities in locations with few opportunities for intergroup contact.

Originality/Value By testing the mediating effects of perceived surface-level and deep-level similarity, this study contributes to our understanding of the mechanism linking the interaction between race composition and location with applicant attraction.

Keywords Race composition · Similarity-attraction · Social identity $\cdot$ Intergroup contact

\section{Introduction}

Organizations that utilize all talents in the labor market are likely to attain sustainable competitive advantage through a diverse workforce that is valuable and scarce (Richard 2000). By hiring employees with various demographic and personal characteristics, employers may be better able to understand the marketplace (Smedley et al. 2004) and develop more creative and innovative solutions to everyday work problems (Cox 2001).

To achieve a diverse workforce, organizations must appear as an attractive employer in the eyes of both minority and majority applicants (Allen et al. 2007; Barber 1998). Past research has consistently shown that minority applicant attraction is influenced by the race composition of organizational representatives featured in recruitment advertising; in contrast, majority applicants are unaffected by the race composition of organizational representatives 
(Avery 2003; Avery et al. 2004; Perkins et al. 2000; Wells 2008). The differential effect of race composition on minority and majority applicants highlights the important role that contextual variables play in the relationship between race composition and applicant attraction.

We aim to contribute to the literature by examining another important contextual variable-locations that vary on the levels of intergroup contact between majority and minority communities. We theorize that different geographic locations provide different levels of opportunity for minority group members to interact with members of a majority group. Social identity theory (Tajfel and Turner 1986) and the social categorization perspective (Turner 1987) suggest that people tend to categorize self and others into meaningful social categories such as race (e.g., White versus Black). In order to enhance self-identity, individuals psychologically maximize the differences between two groups (Kramer 1991), evaluating members of their own group especially favorably. However, as a result of increased intergroup interactions, individuals may re-categorize in-group and former out-group members as a new in-group (Brown and Turner 1981; Gaertner and Dovidio 2000; Gaertner et al. 1996). Individuals who experience more intergroup interactions may form more positive attitudes toward racially dissimilar individuals perceiving these previous out-group members as belonging to their own social category. Consequently, the effects of race composition in recruitment advertising may be weaker for minorities that are in high intergroup contact locations compared to minorities in low intergroup contact locations.

Our main goal, however, is to identify the underlying mechanism linking the interactive effect of race composition and location with applicant attraction. In a location that offers many opportunities for intergroup contact, group members learn more about members of other groups (Pettigrew and Tropp 2008) and form more accurate perceptions about other groups (Zellmer-Bruhn et al. 2008), particularly in terms of underlying values or deep-level attributes (Harrison et al. 1998, 2002). Consistent with the similarity-attraction paradigm (Byrne 1971), the perception of deep-level similarity in turn predicts the attraction that individuals have for one another (Goldberg 2005; Graves and Powell 1995). Based on these ideas, we propose that the applicant's perceived surface-level (i.e., race) and deep-level (i.e., values, personality, and attitudes) similarity with representatives depicted in job advertisements will mediate the moderating effect of location on the relationship between race composition and applicant attraction. Figure 1 presents the proposed study model.

Finally, we examine the above research aims in a theoretically significant research context. Most of the research on attracting minority job applicants has been conducted in the United States and focused on Black Americans as the minority group (e.g., Avery 2003; Avery et al. 2004). The present study involves minority Malaysian-Chinese in Malaysia and in Australia.

Malaysia is a multiracial country in which there is a clear numerical distinction between majority (i.e., Malay) and minority (i.e., Chinese) groups. Of Malaysia's total population (28.30 million people), $67.40 \%$ are Bumiputera (majority are Malays), $24.60 \%$ are Chinese, $7.3 \%$ are Indians, and $0.70 \%$ are members of other groups (Department of Statistics Malaysia 2010). Malaysian-Chinese are people of Chinese heritage who were born in Malaysia and hold Malaysian citizenship. They may be second- or third-generation descendants of Chinese immigrants.

Even though they are a numerical minority, Chinese in Malaysia enjoy a higher socioeconomic status than the majority group of Malays (Agadjanian and Liew 2005). Prior recruitment research has examined minority groups that are disadvantaged in terms of economic and social status relative to the majority group (Pratto et al. 2000), so that the effect of numerical minority status is confounded with lower socioeconomic status. As a result, it is unclear whether the greater sensitivity to diversity recruitment cues exhibited by racial minorities stems from their numerical distinctiveness or their disadvantaged status. A sample of the Malaysian-Chinese community allows us to examine numerical minority effects with a high socioeconomic status group. Finally, the location contexts of Australia and Malaysia provide two settings with low and high intergroup contact, respectively, between the minority MalaysianChinese and the majority Malaysian-Malays.

\section{Theoretical Background and Hypotheses}

\section{Effects of Race Composition on Applicant Attraction}

Research on the effects of race composition on applicant attraction has shown that minority members are more attracted to organizations that feature minority representatives in their recruitment materials than to organizations that do not (Avery 2003; Avery et al. 2004). Further, attraction increases as the percentage of minority representatives featured increases (Perkins et al. 2000; Wells 2008).

For example, Perkins et al. (2000) examined the effect of race composition on students' ratings of organizational attractiveness, perceived compatibility between the student and the organization, and favorability of the organization's image. Race composition was manipulated by changing the ratio of Black to White employees represented in the advertisement. Black employees constituted 0, 10, 30, or 
Proposed Relationships among Study Variables

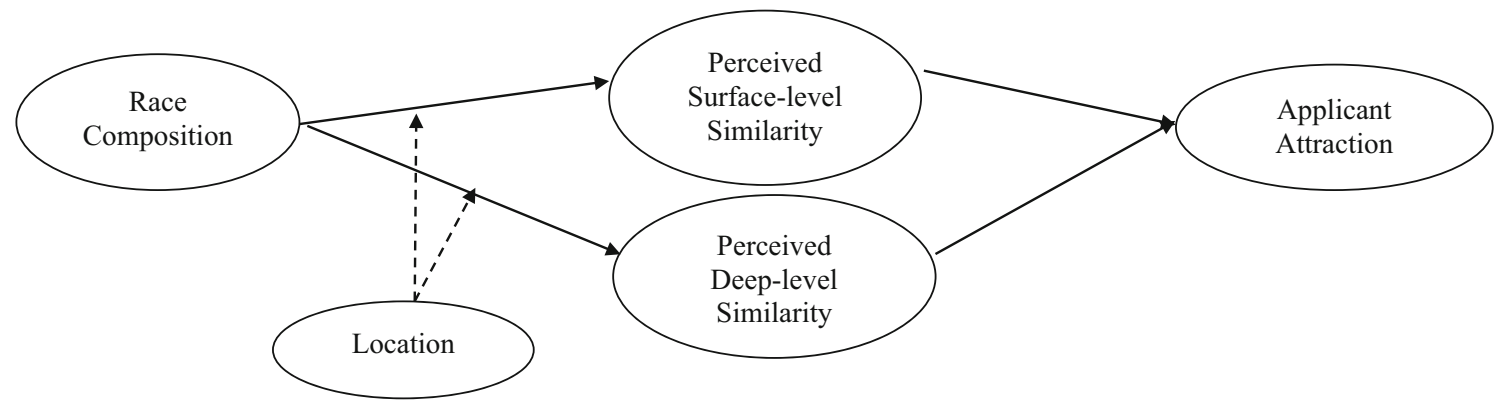

Fig. 1 Proposed relationships among study variables

$50 \%$ of the total 10 employees. Black students were more attracted to an organization that displayed at least one Black employee (i.e., $10 \%$ of the total employees) in the advertisement. Further, Black students' ratings on all three outcome variables increased as the ratio of Black employees increased (Perkins et al. 2000). A similar pattern of results has been found in other studies (Avery 2003; Avery et al. 2004; Wells 2008).

In general, minority participants are more attracted to organizations featuring minority representatives than to organizations featuring majority representatives. In contrast, majority participants are less affected by the race composition of organizational representatives featured than minority participants (Avery 2003; Avery et al. 2004; Perkins et al. 2000; Wells 2008). Hence, an organization that features minority representatives in an advertisement is likely to attract more minority applicants without discouraging majority applicants.

Two theoretical perspectives are used to explain the effects of race composition on applicant attraction. First, social identity/categorization theory (Tajfel and Turner 1986; Turner 1987) suggests that people categorize themselves and others into social groups. Categorization allows an individual to organize his or her social environment and define himself or herself and others (Ashforth and Mael 1989). Further, individuals are driven to attain and/or maintain a positive image of their own group as they derive positive feelings from their own group's successes (Ashforth and Mael 1989; Hogg and Terry 2000; Tajfel and Turner 1986). By maximizing the differences between ingroups and out-groups and evaluating members of their own group especially favorably, individuals may attain a positive self and social identity (Kramer 1991).

Second, a related theoretical perspective-the similarity-attraction paradigm-predicts that individuals are attracted to people with similar attitudes (Byrne 1971). Early studies found support for the paradigm (Byrne 1971; Byrne and Clore 1970) and later research extended the paradigm to examine the effect of demographic similarity
(Ferris et al. 1994; Tsui and O'Reilly 1989). People are attracted to demographically similar (e.g., same race or gender) others believing that these individuals have attitudes similar to their own (Baskett 1973). Demographic attributes such as race are often used as proxies for inferring interpersonal similarity (Elsass and Graves 1997).

In the recruitment context, minority applicants tend to favor organizations featuring a group of minority (i.e., ingroup) rather than majority (i.e., out-group) representatives (Avery 2003) even though they have not interacted with those representatives. Demographic attributes such as race can be easily noticed even when there is little or no interaction (Zellmer-Bruhn et al. 2008). Further, applicants are more attracted to, and more likely to choose to work for, an organization whose workforce has characteristics similar to their own (Riordan 2000; Schneider 1987). For instance, individuals may be more attracted to a firm that hires a group of employees who are racially similar to them, anticipating that these employees share their personal values and attitudes (Avery et al. 2004).

\section{Mediated Moderation: Location as Moderator and Perceived Surface- and Deep-Level Similarity as Mediators}

In this study, we examine the moderating effect of locations (Australia versus Malaysia) that vary on intergroup contact. According to the contact hypothesis (Allport 1954; Williams 1947), interaction among members of different social groups reduces the negative attitudes that individuals have toward out-group members. Contact tends to be more effective in reducing bias when (1) members have equal power and status; (2) members have common goals; (3) members are engaged in interdependent or cooperative tasks; (4) the contact occurs in a context that supports egalitarian norms; and (5) members are given opportunities to develop personal acquaintances and intergroup friendships (Dovidio et al. 2003; Pettigrew 1998). Although the conditions for optimum contact may enhance the positive 
effects of contact, they are not essential (Pettigrew and Tropp 2006). A meta-analysis of 713 independent samples from 515 studies supported the contact hypothesis. Individuals show less prejudice toward out-group members as the amount of contact between the two groups increases (Pettigrew and Tropp 2006).

Based on the contact literature, intergroup interaction may foster a mutual understanding between the minority and the majority groups, which in turn mitigates the initial negative perceptions and increases the attraction that one group has toward another (Brewer and Miller 1984; Cook 1978; Pettigrew 1971). Individuals who have interacted with individuals from different cultures are more likely to recognize that the stereotypes they hold about the outgroup do not apply to all members of the group (Shrivastava and Gregory 2009; Wolsko et al. 2003). They are more likely to hold accurate perceptions about their similarities or dissimilarities with others (Shrivastava and Gregory 2009; Zellmer-Bruhn et al. 2008) as a result of disconfirming the negative stereotypes that they had about outgroup members (Wolsko et al. 2003). Studies showed that increased contact among members of two groups fostered favorable attitudes toward the out-group (Biernat 1990; Brown et al. 2007).

Based on the contact hypothesis (Allport 1954; Williams 1947), minority members in locations that offer few opportunities for intergroup interactions are more likely to be affected by the race composition of organizational representatives featured in recruitment advertising than minority members in locations that offer many opportunities for intergroup interactions. Minority members in locations with higher intergroup contact opportunities are more likely to form favorable attitudes toward out-group members and display less positive bias toward in-group members (Brewer and Miller 1984; Gaertner et al. 1996). Hence, we predict that the effect of race composition on applicant attraction will be stronger for minority Malaysian-Chinese participants in Australia (i.e., a location that offers few intergroup contact opportunities) than for minority Malaysian-Chinese participants in Malaysia (i.e., a location that offers many intergroup contact opportunities).

Perceived similarity refers to the extent to which individuals think and believe that they are similar to others (Turban and Jones 1988). It is important to study perceived similarity because the effect of actual similarity on attraction may be facilitated by the extent to which the individual believes himself/herself to be similar to the other person (Goldberg 2005; Riordan 2000). Past research showed that Black Americans displayed a stronger effect of race composition on organizational attractiveness than White Americans, and the moderating effect was mediated by perceived similarity (Avery et al. 2004).
Social identity/categorization theory (Tajfel and Turner 1986; Turner 1987) suggests that individuals show ingroup favoritism and out-group rejection in order to enhance their self-identity. Employees often use their race as a basis for self and other categorization (Chattopadhyay et al. 2004; Hogg and Terry 2000). Same-race individuals are perceived as more racially similar (Pelled 1996). But they are also perceived as more favorable (Kramer 1991; Tsui et al. 1992), leading to greater applicant attraction.

However, individuals in locations that offer many opportunities for intergroup interaction are less likely to hold prejudiced views toward out-group members. Specifically, they may be less likely to categorize self and others based on race and more likely to view racially similar and dissimilar members as individual entities rather than as in-group and out-group members (i.e., de-categorization; Brewer and Miller 1984; Dovidio et al. 2003). Further, they may categorize themselves and members of another group (out-group) as belonging to a new in-group (i.e., re-categorization; Anastasio et al. 1997; Gaertner et al. 1993, 1994). As a result, these individuals are more likely to form positive attitudes toward previous out-group members (Gaertner et al. 1996) and less likely to exhibit especially favorable attitudes toward their own group members (Brewer 1979; Turner 1985). In short, intergroup contact may reduce prejudice and facilitate attraction through the perception of race similarity with out-group members.

Based on above reasoning, we propose two hypotheses. The first hypothesis predicts the overall effect of race composition $\mathrm{x}$ location interaction on applicant attraction. The second hypothesis predicts the mediating effect of perceived surface-level similarity.

Hypothesis 1 There will be a two-way interactive effect of race composition and location on applicant attraction. The effect of race composition will be stronger for minority Malaysian-Chinese participants in Australia than for minority Malaysian-Chinese participants in Malaysia.

Hypothesis 2 The two-way interactive effect of race composition and location on applicant attraction will be mediated by perceived surface-level similarity between applicant and representatives.

The similarity-attraction paradigm (Byrne 1971) suggests that people are attracted to other people who hold similar attitudes. Individuals may be more attracted to racially similar others because they infer deep-level similarity (e.g., similarity in values or attitudes). However, as intergroup contact increases, individuals develop knowledge about out-group members and recognize the similarities that they have with others (Pettigrew and Tropp 2008), particularly with respect to deep-level attributes (Zellmer- 
Bruhn et al. 2008). As a result of re-categorization (Anastasio et al. 1997; Gaertner et al. 1993, 1994), individuals who have regular interactions with out-group members may be more likely to view themselves and members of another group (out-group) as sharing the values, personality, and attitudes of the in-group members. Hence, the effect of race composition of organizational representatives may be weaker for individuals in locations that offer many opportunities for intergroup interactions (as a result of recognizing the deep-level similarities that they have with the racially dissimilar representatives) than for individuals in locations that offer few opportunities for intergroup interactions.

Hypothesis 3 The two-way interactive effects of race composition and location on applicant attraction will be mediated by perceived deep-level similarity between applicant and representatives.

In this study, we propose that perceived deep-level similarity will be a stronger mediator in the interactive effect of race composition and location on application attraction than perceived surface-level similarity. Perception of similarity in terms of values and attitudes (deep-level) is inferred from surface-level attributes (e.g., race). Consistent with signaling theory (Spence 1973), we propose that potential job applicants form an initial perception of race similarity based on the advertisement. However, it is their anticipated deep-level similarity with the featured representatives that predicts applicants' attraction to the organization (Casper et al. 2013; Harrison et al. 1998). Empirical evidence showed that targeted recruitment is more effective when deep-level attributes are featured in the job advertisement as compared to surface-level attributes (Casper et al. 2013). Based on signaling theory and the perceived similarity literature, we hypothesize that:

Hypothesis 4 Perceived deep-level similarity will be a stronger mediator in the two-way interactive effects of race composition and intergroup contact on applicant attraction than perceived surface-level similarity.

\section{Method}

\section{Study Context and Design}

The study used a 2 (low vs. high contact location: Australia vs. Malaysia) $\times 3$ (race composition in the advertisement: $100 \%$ Malay vs. $50 \%$ Malay-50\% Chinese vs. $100 \%$ Chinese) between participants design. This study was conducted with Malaysian-Chinese students studying in Malaysia and Australia.
Students pursue a university degree in order to improve their employment opportunities and most university students enter the job market immediately upon graduation. In Malaysia, for example, most university students are employed within six months of graduation (Bernama 2012). Because students are future job seekers, student samples are common in recruitment research (e.g., Avery 2003; Kraichy and Chapman 2014). Research using university students yields effect sizes comparable to those using job applicants (Chapman et al. 2005).

\section{Low and High Contact Location}

University location (Malaysia versus Australia) was used as a naturally occurring variation of the frequency of contact between the minority Malaysian-Chinese population and the majority Malaysian-Malay population. The Malaysian public university context provided high intergroup contact. The New Economic Policy (NEP, 1969-1971) gives priority to majority Malays in education and employment opportunities (The Economist 2005). For instance, more than $70 \%$ of the public university places are reserved for majority Malaysian-Malay individuals (Pak 2013; Tan and Sharma 2013). The demographic composition of universities in Malaysia offers many opportunities for Malaysian-Chinese students to meet and become acquainted with Malaysian-Malay individuals-a fundamental condition of the contact hypothesis (Avery and Thomas 2004; Gottfredson et al. 2008). Due to the large number of majority Malay students in public universities in Malaysia, these universities provide more opportunities for contact with Malay individuals as compared to universities in Australia.

The Australian university context provided low intergroup contact. As a result of the preferential treatment given to the majority Malaysian-Malays in Malaysia, only a small percentage of minority group members (including Malaysian-Chinese) are able to secure a place in Malaysian universities despite excellent grades (Tan and Sharma 2013). Given their high socioeconomic status, it is not unusual for minority Malaysian-Chinese parents to send their children abroad for tertiary education. Minority Malaysian-Chinese students who are in universities overseas could be as competent as those who got accepted into public universities in Malaysia. In this research, "Malaysian-Chinese in Australia" refers to Chinese citizens of Malaysia who went to Australia to study. Most Malaysians studying overseas are of non-Malay descent (e.g., of Chinese ethnicity) (Ancheh 2005; Tan 2002). Due to the limited number of majority Malay students in Australian universities, universities in Australia provide fewer opportunities for contact with majority Malaysian-Malays as compared to public universities in Malaysia. 
The university environment was the ideal setting in which to examine the effects of variations in intergroup contact. University students are often involved in team work or group assignments as part of their course requirements. Team work facilitates the perception of common goals and common goals foster interdependence among team members. In most universities, students enjoy equal power and education status. Hence, regardless of the location where the contact occurred (i.e., Malaysia or Australia), the interactions in which these university students engaged met the optimum conditions specified by the contact hypothesis (Allport 1954; Williams 1947). Therefore, the student's location (Australia versus Malaysia) should generate different levels of contact and attitude change.

We conducted a pilot study to confirm that the two locations generated different levels of intergroup contact. We recruited 31 Malaysian-Chinese individuals (12 in Malaysia and 19 in Australia) to respond to four questions about their interpersonal contact with Malaysian-Malays: How many Malay friends do you have $(1=$ None; $5=10$ or more)? How often do you spend time (or interact) with Malay individuals $(1=$ Rarely; $5=$ Very often $)$ ? How often do you see or meet Malay individuals ( $1=$ Rarely; $5=$ Very often $)$ ? How close are you to Malay individuals $(1=$ Very distant; $5=$ Very close $)$ ? The four items loaded onto a single factor and formed a reliable scale (alpha $=.89)$. A $t$ test confirmed that the Malaysian-Chinese participants in Malaysia $(M=3.67, S D=.54)$ experienced significantly greater contact with Malaysian-Malays than the Malaysian-Chinese participants in Australia $(M=2.64, S D=1.12), t(27.52)=3.41, p<.01$, effect size $r=.55$.

\section{Race Composition in the Advertisement}

Three job advertisements (i.e., ads) were created based on information obtained from the web pages of multinational organizations in Malaysia. All three ads similarly depicted the recruiting effort by an organization named Soroton Inc. The ads briefly described Soroton Inc. as an organization that produces a wide range of goods and services and an employer that provides a good package of career opportunities. Following the organization description, we presented four employee testimonials.

The content of the organization information and the employee testimonials was held constant across all three ads (see Appendix for sample ad). The only variation across the ads was the race composition of the employees making the testimonials. Beside each testimonial, the ad presented the picture and name of the employee making the comments. Both the picture and the name cued the employee's race. We pilot tested employee pictures and names to ensure that all employees were perceived as moderately attractive and their names were clearly Malay or Chinese. We showed ten Malaysian students in Australia a list of 12 names and asked them to indicate the person's race (Malay or Chinese). Participants agreed $100 \%$ on the race of the names used in the stimulus ads.

We used two male and two female employees in each ad. There were three race composition conditions: $100 \%$ majority Malay (i.e., two Malay males and two Malay females), $50 \%$ majority Malay and $50 \%$ minority Chinese (i.e., one Malay male and one Malay female; one Chinese male and one Chinese female), and $100 \%$ minority Chinese (i.e., two Chinese males and two Chinese females). We randomly assigned participants to one of the three race composition conditions and they were not aware of the other conditions.

We included a single-item manipulation check at the end of the survey: "Based on the advertisement, I believe that Soroton Inc. comprises employees of various races" $(1=$ strongly disagree to $7=$ strongly agree $)$. A one-way ANOVA demonstrated that there are differences in the perception of racial diversity between the conditions, Welch $F(2,208.60)=44.10, p<.001$. Post hoc GamesHowell statistics showed that there are significant differences between the $100 \%$ Chinese and 50/50 conditions $\left(M_{\mathrm{diff}}=1.29, S E=.20, p<.001\right)$ and between the $100 \%$ Malay and $50 / 50$ conditions $\left(M_{\text {diff }}=-1.78, S E=.21\right.$, $p<.001)$. However, the difference between the All-Chinese and All-Malay conditions is non-significant $\left(M_{\mathrm{diff}}=-.49, S E=.24, p=.096\right)$. In conclusion, participants viewed the $50 / 50$ condition as reflecting more racial diversity $(M=5.02, S D=1.24)$ than either the $100 \%$ Malay $(M=3.24, S D=1.77)$ or $100 \%$ Chinese $(M=3.73, S D=1.69)$ conditions.

\section{Sample and Procedures}

Participants were 344 minority Malaysian-Chinese university students (161 Malaysian-Chinese individuals in Malaysia and 183 Malaysian-Chinese individuals in Australia). All participants self-identified as Malaysian-Chinese. The demographic distributions of participants in Malaysia and Australia were very similar. In both locations, the majority of the participants were female $(72.0 \%$ for participants in Malaysia and $63.9 \%$ for participants in Australia) and all participants were from a similar age group (20-27 years for participants in Malaysia and 17-28 years for participants in Australia).

We recruited participants in Malaysia through a letter of introduction to three public universities. Upon the dean's approval, the survey was conducted in lecture halls. We approached participants in Australia through an invitation email to four student associations whose members were 
mainly Malaysian students studying in one of the state's universities. The invitation email was circulated to all members of each association. We asked members to reply to the email or to contact the principal researcher directly if they were interested in participating. In order to increase the study sample size, we also approached students on university campuses and other public places (e.g., shopping malls, cafes).

To ensure consistency, the same researcher administered all the surveys and delivered a standard set of instructions to participants. First, participants were provided a brief introduction to the researcher and the research topic. The researcher informed participants that the purpose of the study was to examine the effect of different advertisements on organizational attractiveness. Second, regardless of where they wanted their future job to be, the researcher instructed participants to imagine that they were looking for a job in Malaysia. Based on a one-item measure, 'In the most likely terms, where do you plan to work after you graduate? (Australia/Malaysia/Other places-Please specify), we found that $67.8 \%$ of Malaysian-Chinese in Australia planned to look for a job in Australia, whereas $70.2 \%$ of Malaysian-Chinese in Malaysia planned to stay in Malaysia. Hence, the instruction is important to ensure that participants perceived the advertisement as personally relevant and that the job search location was uniform for all participants. Further, the researcher emphasized that the advertised company was a general organization producing a variety of goods and services, and thus, it hires graduates from all fields. After the verbal instructions, the researcher gave participants a survey pack containing an information sheet, a consent form, and the survey. The researcher asked participants to read and sign the consent form if they agreed to participate. The survey took about $20 \mathrm{~min}$ to complete. The researcher thanked participants and gave each one a candy at the end of the session.

\section{Measures}

We included three continuous variables in the survey and we measured all items using a Likert scale $(1=$ strongly disagree to 7 = strongly agree).

\section{Perceived Surface-Level Similarity}

We developed a one-item perceived surface-level similarity measure based on Cunningham's (2007) actual racial dissimilarity measure. Single-item measures are acceptable (and even preferred) when the construct is specifically defined and unambiguous (Sackett and Larson 1990; Wanous et al. 1997). In our materials, participants were exposed to representatives who were unambiguously members of two familiar racial groups (i.e., Malaysian-
Malays and Malaysian-Chinese). The item was: "With respect to race, I think I am very similar to the employees who work at Soroton Inc." "Race" is used instead of "ethnicity" in our item because "race" is more frequently used in Malaysian classrooms, media, and academic writing (Nakamura 2012).

\section{Perceived Deep-Level Similarity}

We developed three items based on the conceptualization of perceived deep-level similarity by Cunningham (2007) and Harrison et al. (2002). Consistent with the similarityattraction literature (Elsass and Graves 1997; Harrison et al. 1998; Tsui et al. 1992), although respondents did not receive personality information from the recruitment advertising, respondents were likely to draw inferences about personality similarity based on the race of the representatives in the recruitment advertising. The items used in this study measured the degree to which participants perceived themselves as similar to people working in the organization in terms of personal values, personality, and attitudes. A sample item was: "With respect to personality, I think I am very similar to the employees who work at Soroton Inc." The internal consistency of this measure was 89 .

\section{Applicant Attraction}

We measured participants' attraction to the organization using the three-item scale developed by Highhouse et al. (2003). A sample item was: 'Soroton Inc. is attractive to me as a place for employment.' The internal consistency of this measure was .88.

\section{Demographic Variables}

We included two demographic variables. Participants reported their age in response to an open-ended question and reported their gender by choosing either a male or female category.

\section{Results}

\section{Descriptive Statistics}

Table 1 presents the means, standard deviations, and correlations among study variables. The zero-order correlations show positive associations among the two similarity measures and attraction. The positive relationship between location and applicant attraction indicates that participants in Malaysia rated the organization as more attractive than participants in Australia. 
Table 1 Means, standard deviations, and correlations

\begin{tabular}{lccccc}
\hline Variable & Mean & $S D$ & 1 & 2 & 3 \\
\hline 1. Location & .47 & .50 & & \\
2. Applicant attraction & 4.35 & 1.06 & $.24 * * *$ & & \\
3. Perceived surface-level similarity & 4.34 & 1.47 & .08 & $.36^{* * *}$ & \\
4. Perceived deep-level similarity & 4.28 & 1.09 & .06 & $.53^{* * *}$ & $.51^{* * * *}$ \\
\hline$n=344$ & & & & \\
Location: $0=$ Australia (few intergroup contact opportunities); 1 = Malaysia (many intergroup contact \\
opportunities) \\
$* * * p<.001$
\end{tabular}

\section{Tests of Hypotheses}

\section{The Moderating Effect of Location}

Hypothesis 1 predicted that location will moderate the effect of race composition on attraction. The result of a two-way Analysis of Variance (ANOVA) showed that the main effects of race composition $(F[2,338]=7.71$, $p<.01, \quad$ partial $\left.\eta^{2}=.04\right)$ and location ( $F \quad[1$, $338]=24.21, p<.001$, partial $\left.\eta^{2}=.07\right)$ on attraction were significant. Tukey's post hoc tests revealed that an organization featuring $50 \%$ Malay-50\% Chinese or $100 \%$ Chinese representatives was perceived as significantly more attractive than an organization featuring $100 \%$ Malay representatives $\left(M_{\text {diff }}=.32, S E=.13\right.$, $p<.05 ; M_{\text {diff }}=.49, S E=.13, p<.01$; respectively). In contrast, the mean difference between the $50 \%$ Malay$50 \%$ Chinese and $100 \%$ Chinese conditions was nonsignificant $\left(M_{\mathrm{diff}}=.17, S E=.13\right.$, n.s. $)$. Further, participants in Malaysia rated the organization as more attractive $(M=4.62, S D=.89)$ than participants in Australia $(M=4.11, S D=1.15)$. As hypothesized, the interaction between race composition and location on applicant attraction was significant $(F[2,338]=3.89, p<.05$, partial $\eta^{2}=.02$ ). Table 2 presents the condition means and standard deviations and Fig. 2 depicts the pattern of results for the interaction effect of race composition and location on applicant attraction. Interestingly, participants in Australia (low intergroup contact location) were less attracted to $100 \%$ Chinese condition than participants in Malaysia (high intergroup contact location) even though both groups of participants were Malaysian-Chinese individuals. We speculate that Malaysian-Chinese in Malaysia who had greater opportunities to interact with Malaysian-Malays might also experience high race salience due to their apparent minority status in Malaysia. They might be more sensitive to race issues in the country and more protective of their own race (e.g., by favoring organizations consisting of in-group individuals more than organizations consisting of out-group members). In contrast, in a highly diverse society like Australia, 'race' might not be the only (or preferred) way of how people categorize self and others. For instance, Malaysian-Chinese in Australia might categorize themselves using their
Table 2 Mean scores for applicant attraction, perceived surface-level similarity, and perceived deep-level similarity by race composition and location

\begin{tabular}{|c|c|c|c|c|c|c|}
\hline \multirow[t]{2}{*}{ Intergroup contact } & \multicolumn{2}{|c|}{$100 \%$ Malay } & \multicolumn{2}{|c|}{$50 \%$ Malay-50\% Chinese } & \multicolumn{2}{|c|}{$100 \%$ Chinese } \\
\hline & Mean & $S D$ & Mean & $S D$ & Mean & $S D$ \\
\hline \multicolumn{7}{|l|}{ Applicant attraction } \\
\hline Malaysia & 4.54 & .77 & 4.51 & .96 & 4.83 & .92 \\
\hline Australia & 3.61 & 1.26 & 4.31 & .87 & 4.35 & 1.17 \\
\hline Total & 4.08 & 1.14 & 4.40 & .91 & 4.57 & 1.09 \\
\hline \multicolumn{7}{|c|}{ Perceived surface-level similarity } \\
\hline Malaysia & 4.04 & 1.38 & 4.35 & 1.14 & 5.06 & 1.27 \\
\hline Australia & 2.89 & 1.52 & 4.68 & 1.03 & 4.95 & 1.36 \\
\hline Total & 3.47 & 1.55 & 4.53 & 1.09 & 5.00 & 1.32 \\
\hline \multicolumn{7}{|c|}{ Perceived deep-level similarity } \\
\hline Malaysia & 4.43 & 1.03 & 4.12 & 1.02 & 4.50 & .85 \\
\hline Australia & 3.82 & 1.37 & 4.36 & .93 & 4.41 & 1.14 \\
\hline Total & 4.13 & 1.24 & 4.25 & .97 & 4.45 & 1.02 \\
\hline
\end{tabular}




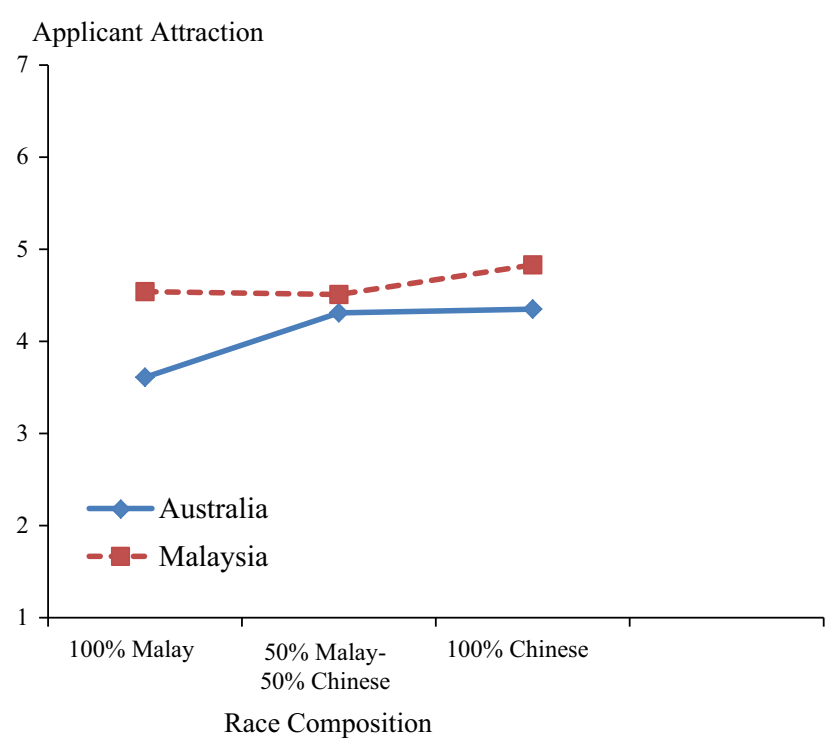

Fig. 2 The interactive effect of race composition and location on applicant attraction

nationality (i.e., Malaysian) rather than their specific racial group (i.e., Malaysian-Chinese) or their residency status (i.e., international vs. local). Further, without the constant reminder of being a minority in Malaysia, Malaysian-Chinese in Australia might be less likely to show in-group bias, leading to a lower attraction score in the $100 \%$ Chinese condition, as compared to MalaysianChinese in Malaysia.

We conducted a simple effects analysis to better understand the interaction effect. The analysis showed that the difference in applicant attraction ratings between participants in locations that offer high and low intergroup contact (Malaysia vs. Australia) was significant in the $100 \%$ Malay $\left(F[1,340]=22.64, p<.001 ; M_{\text {diff }}=.93\right)$ and $100 \%$ Chinese $(F \quad[1,340]=5.20, \quad p<.05$; $\left.M_{\text {diff }}=.48\right)$ conditions but not in the $50 \%$ Malay-50\% Chinese $\left(F[1,340]=.92\right.$, n.s.; $\left.M_{\text {diff }}=.20\right)$ condition. Further, the differences across the three race composition conditions were significant for participants in Australia $(F[2,339]=8.42, p<.001)$ but not for participants in Malaysia $(F[2,339]=1.45$, n.s. $)$. In conclusion, the results supported Hypothesis 1: The effect of race composition would be stronger for minority Malaysian-Chinese participants in Australia than for minority Malaysian-Chinese participants in Malaysia. The support for Hypothesis 1 confirms the overall effect of the two-way interaction on attraction; we next report the results of our main analysisthe indirect effect through perceived surface- and deeplevel similarity.
The Mediating Role of Perceived Surface- and Deep-Level Similarity

We used Hayes' PROCESS macro (http://www.afhayes. com) to test the mediating role of perceived surface-level and perceived deep-level similarity. We used Model 7 to test the effect of two mediators and one moderator within the same model. Two dummy variables were created for the three-categorical independent variable (race composition) using $50 \%$ Malay-50\% Chinese as the reference group (Hayes and Preacher 2014). The two dummy variables are $100 \%$ Malay versus the other two conditions (100\% Chinese and $50 \%$ Malay-50\% Chinese) and $100 \%$ Chinese versus the other two conditions (100\% Malay and $50 \%$ Malay-50\% Chinese). For ease of reading, in the following paragraphs, we use $100 \%$ Malay or $100 \%$ Chinese condition to refer to these two dummy variables. We ran Model 7 two times, each time with one dummy-coded independent variable $(100 \%$ Malay or $100 \%$ Chinese), one moderator (location), and two mediators (perceived surface-level similarity and perceived deep-level similarity). Tables 3 and 4 summarize the two sets of analysis.

Hypotheses 2 and 3 state that the two-way interactive effect of race composition and location on applicant attraction would be mediated by perceived surface-level similarity (H2) and deep-level similarity (H3) between applicant and representatives. Further, hypothesis 4 states that perceived deep-level similarity would be a stronger mediator than perceived surface-level similarity.

As shown in Table 3, when the $100 \%$ Malay condition was the predictor, perceived surface-level similarity was a non-significant mediator $($ Index $=.0554, \mathrm{SE}=.0630$, LLCI $=-.0575$, ULCI $=.2003$ ) but perceived deeplevel similarity was a significant mediator (Index = $.3277, \mathrm{SE}=.1332, \mathrm{LLCI}=.1075, \mathrm{ULCI}=.6076)$. The mediating effect of perceived deep-level similarity (.3277) is nearly six times the effect of perceived surface-level similarity (.0554). Specifically, perceived deep-level similarity significantly mediated the $100 \%$ Malay and attraction relationship in Australia (Index $=-.2238$, $\mathrm{SE}=.1042 ;$ LLCI $=-.4314$, ULCI $=-.0354$ ) but not in Malaysia (Index $=.1039, \quad \mathrm{SE}=.0910, \quad$ LLCI $=$ -.0574 , ULCI $=.2983)$. In contrast, when the $100 \%$ Chinese condition was the predictor (see Table 4), the index of moderated mediation was non-significant for both perceived surface-level similarity (Index $=-.0127$, $\mathrm{SE}=.0248$, LLCI $=-.1042$, ULCI $=.0104)$ and perceived deep-level similarity $($ Index $=-.0416, \quad \mathrm{SE}=$ .1171 , LLCI $=-.2808$, ULCI $=.1775)$. 
J Bus Psychol

Table 3 Conditional indirect effect of $100 \%$ Malay versus two other conditions on applicant attraction in two locations, perceived surfacelevel (SURFACE) and deeplevel (DEEP) similarity as mediators

Table 4 Conditional indirect effect of $100 \%$ Chinese versus two other conditions on applicant attraction in two locations, perceived surfacelevel (SURFACE) and deeplevel (DEEP) similarity as mediators

\begin{tabular}{lrlcc}
\hline & Index & Boot SE & Boot LLCI & Boot ULCI \\
\hline Mediator 1: SURFACE & .0554 & .0630 & -.0575 & .2003 \\
Moderator level 1: Australia & -.0744 & .0813 & -.2394 & .0859 \\
Moderator level 2: Malaysia & -.0190 & .0258 & -.1037 & .0122 \\
Mediator 2: DEEP & .3277 & .1332 & .1075 & .6076 \\
Moderator level 1: Australia & -.2238 & .1042 & -.4314 & -.0354 \\
Moderator level 2: Malaysia & .1039 & .0910 & -.0574 & .2983 \\
\hline
\end{tabular}

\begin{tabular}{lcccc}
\hline & Index & Boot SE & Boot LLCI & Boot ULCI \\
\hline Mediator 1: SURFACE & -.0127 & .0248 & -.1042 & .0104 \\
Moderator level 1: Australia & .0263 & .0325 & -.0198 & .1158 \\
Moderator level 2: Malaysia & .0136 & .0212 & -.0115 & .0812 \\
Mediator 2: DEEP & -.0416 & .1171 & -.2808 & .1775 \\
Moderator level 1: Australia & .1146 & .0896 & -.0583 & .3036 \\
Moderator level 2: Malaysia & .0730 & .0833 & -.0920 & .2407 \\
\hline
\end{tabular}

In conclusion, hypothesis 2 is not supported but hypotheses 3 and 4 are supported-only perceived deeplevel similarity significantly mediated the effect of demographic composition (100\% Malay contrasted against the other conditions) in the Australian context (H3) and perceived deep-level similarity is a stronger mediator than perceived surface-level similarity (H4).

\section{Discussion}

The rising level of applicant pool diversity requires organizations to attract and recruit minority applicants. More importantly, a diverse workforce represents a valuable resource that can help an employer achieve a sustainable competitive edge (Richard 2000). Organizations often use recruitment advertising to attract minority applicants by indicating their diversity values or stance. For example, employers that feature a group of minority representatives in recruitment materials are more likely to attract minority applicants than employers that do not (Avery 2003; Avery et al. 2004; Perkins et al. 2000). However, not all applicants are equally affected by diversity signals. Consistent with our hypothesis, minority Malaysian-Chinese participants in Malaysia were less affected by the race composition of organizational representatives featured in recruitment advertising than minority Malaysian-Chinese participants in Australia. Further, this moderating effect of location was mediated by perceived deep-level (but not surface-level) similarity.

Our findings contribute to the literature in several ways. Our study advances the literature by examining the effect of location in the race composition and attraction relationship. The role of context (as captured in the two locations in this study) has been underappreciated in organizational research (Johns 2006). This study included context as a main variable, not just as a control, and was able to derive theoretically and practically meaningful insights. Consistent with the contact hypothesis (Allport 1954; Williams 1947), we found that Malaysian-Chinese participants in a location that offers many opportunities for intergroup interactions (i.e., Malaysia) were less prejudiced toward, and more likely to perceive similarities with racially dissimilar others. Consequently, minority Malaysian-Chinese individuals in Malaysia were less likely to reject organizations featuring a group of representatives that included Malaysian-Malays. Therefore, MalaysianChinese in Malaysia were less affected by the race composition of organizational representatives than MalaysianChinese in Australia (a location that offers few opportunities for intergroup interactions).

The significant interactive effects of race composition and location supported the contact hypothesis (Allport 1954; Williams 1947). Intergroup interaction may foster a mutual understanding between the minority and the majority groups, which in turn mitigates the initial negative perceptions and increases the attraction that one group has toward another (Brewer and Miller 1984; Cook 1978; Pettigrew 1971). As intergroup contact increases, minority members are less likely to hold negative perceptions and more likely to form favorable impressions toward outgroup (i.e., majority) members. As a result, minority Malaysian-Chinese students in a location that offers many intergroup interaction opportunities (e.g., Malaysia) may hold more favorable attitudes toward racially dissimilar (i.e., out-group) members and thus, be less likely to reject 
organizations featuring a group of representatives who are racially dissimilar to them than minority Malaysian-Chinese students in a location that offers few intergroup interaction opportunities (e.g., Australia).

The key contribution of the present study is that it has provided insight into why minority members who in a location that offers few intergroup interaction opportunities are more affected by race composition. The two-way interactive effect on applicant attraction was mediated by perceived deep-level but not surface-level similarity. Both social identity theory (Tajfel and Turner 1986) and the similarity-attraction paradigm (Byrne 1971) note that individuals are more attracted to similar others. Although these theoretical perspectives are commonly used in combination to explain the effect of overall similarity across multiple diversity dimensions, these theoretical perspectives have not been clearly distinguished by past researchers (Avery et al. 2004). The current study findings suggest that each theory has a different focus in its explanation of actual similarity effects. Given that most of the diversity research has relied on these two theoretical perspectives, diversity researchers should further identify their points of divergence and explicitly test their competing predictions to clarify the mechanism underlying diversity effects.

Consistent with Casper et al. (2013) findings, the present study found that perceived deep-level similarity is a stronger mediator in the interactive effect of race composition and location on applicant attraction than perceived surface-level similarity. We proposed that perception of deep-level similarity (e.g., values and attitudes) was inferred based on surface-level attributes (i.e., race) and potential job applicants form an initial perception of race similarity based on the advertisement (Spence 1973). However, it is their anticipated deep-level similarity with the featured representatives that predicts applicants' attraction to the organization (Casper et al. 2013; Harrison et al. 1998). The present study supported the argument of signaling theory (Spence 1973) as well as the similarityattraction paradigm (Byrne 1971).

Finally, the present study demonstrates that minority participants from a more affluent background exhibit a similar pattern of responses as minority members who are in a disadvantaged position (Avery et al. 2004). Unlike racial minority groups in Western societies (e.g., the United States or United Kingdom), minority Chinese individuals in Malaysia enjoy a relatively high social status as compared to majority Malay individuals (Agadjanian and Liew 2005). Since many decades, Malaysian-Chinese are the advantaged 'rich' racial group (Abdul Khalid 2011), whereas African Americans are the marginalized group in the US (Plumer 2013; WealthInequality.org 2015). Findings of the present study suggest that minority members in
Malaysia are as sensitive toward racial issues as minority members in Western societies. Past research suggests that individuals' behavior in organizational settings is affected by numerical representation (Kanter 1977; Li et al. 1999). But in Western contexts, numerical representation is usually confounded with socioeconomic status. The present study eliminates the possible confounding effect of low numerical representation and low socioeconomic status. It is the minority members' numerical representation and not their socioeconomic status that makes them sensitive to diversity signals. We acknowledge that the result of this present research is preliminary and strongly recommend our results to be replicated in other contexts. It will be interesting to see if members of wealthier immigrant groups in the United States (e.g., Asian Americans and Cuban Americans; WealthInequality.org 2015) display the same similarity-attraction effects that African Americans do.

\section{Practical Implications}

Several practical implications can be drawn from the study findings. First, featuring minority representatives in recruitment advertising is beneficial for attracting racial minority applicants. This implication is consistent across Western and non-Western cultures. Further, the inclusion of minority representatives is more important than the proportion of minority representatives (Wells 2008). Consistent with past studies, the present research found that minority applicants were equally attracted to organizations featuring a homogenous group of minority representatives as to organizations featuring a group of racially diverse representatives (Wells 2008). Hence, employers should utilize recruitment materials to enhance their reputation or image as an attractive employer (Cable and Graham 2000; Carless and Imber 2007). Applicants use information in the recruitment materials as signals of the organization's commitment to, or values for, diversity (Carless 2005; Rynes 1991). Sending diversity messages through recruitment materials is an effective yet economical strategy for attracting minority applicants and achieving workforce diversity (Avery 2003; Avery et al. 2004).

Second, it is important for an employing organization to foster the perception of similarity (with respect to personal values, personality, and attitudes) between minority applicants and the featured representatives. The significant mediating effect of perceived deep-level similarity suggests that minority applicants are attracted to an organization that features minority representatives because they believe that the organization's employees are similar to them in relation to personal values, personality, and attitudes. Consistent with the similarity-attraction paradigm (Byrne 1971), organizations should emphasize the 
attitudinal similarity between minority applicants and organizational representatives rather than merely including minority employees in recruitment advertising. Employers may wish to express their organizational culture or organizational values in recruitment advertising to foster perceptions of deep-level similarity between applicants and the organization's workforce (Cable and Judge 1996).

Lastly, multinational organizations should recognize the importance of diversity signals in their recruitment campaigns. Although minority Malaysian-Chinese individuals in Malaysia enjoy a relatively high status in Malaysia (Agadjanian and Liew 2005), findings of the present research suggest that they are as sensitive to diversity signals as minority group members are in Western societies. Particularly for organizations that aim to recruit minority applicants from a community comprising racially similar individuals (i.e., very few opportunities for intergroup interactions), employers should place more emphasis on fostering the perception of deep-level (e.g., attitudinal) similarity between minority applicants and organizational representatives. Findings of the present study support and extend previous research in non-Western society by suggesting that the effect of race composition on attraction is particularly strong for minority members in a location that offers few opportunities for intergroup interaction. Thus, organizations should not neglect diversity messages when recruiting employees across contexts.

\section{Study Strengths and Limitations}

This research was based on a between subjects experimental design and used university location as a moderator. Therefore, our primary findings of the main effect of race composition on attraction and the moderating effect of location are not affected by a percept-percept relationship. The main effect is based on an experimentally manipulated (between-participants) factor (race composition) and its effects on organizational attraction. The moderated relationship is based on the experimentally manipulated factor (race composition) in combination with a measured contextual variable (participation location), and therefore is not affected by common method variance and is unlikely to have generated inflated correlations (Crampton and Wagner 1994; Podsakoff and Organ 1986).

However, the evidence that perceived similarity mediates this moderated relationship does involve a perceptpercept relationship between perceived similarity and attraction (Podsakoff et al. 2003). It is difficult to avoid percept-percept relationships when researchers are studying a relationship between two perceptual variables (perceived similarity and applicant attraction; Podsakoff and Organ 1986). Future research should examine these relationships in field contexts that allow researchers to predict jobseeker behavior that follows from attraction (e.g., applying for jobs, accepting interview invitations, and choosing among job offers; Chapman et al. 2005).

The present study found that applicant attraction was lower in the sample in Australia for all conditions than for the sample in Malaysia. We suspect that plans to return to Malaysia could be a confounding factor in the study such that individuals who are in a location that offers many opportunities for intergroup interaction (i.e., Malaysia) were already in the location where the job was offered (Malaysia). Our results showed that most Malaysian-Chinese in Australia (67.8\%) planned to look for a job in Australia, whereas most Malaysian-Chinese in Malaysia $(70.2 \%)$ planned to stay in Malaysia. However, note that this difference in location-based preference is unlikely to affect the finding of an interaction between location and race composition (as explained by the contact hypothesis). Analyses controlling for plans of returning to Malaysia generated similar results as those reported in the earlier section.

Our pilot study demonstrated that minority MalaysianChinese experience more intergroup contact with majority Malaysian-Malays in Malaysia than they do in Australia, but we did not directly measure the amount or quality of contact that our Malaysian-Chinese research participants were currently having, or have had in the past, with Malaysian-Malays. With the pilot study results, we are not able to draw strong conclusions due to the small sample size and homogeneity of the pilot study sample. We used intergroup contact theory to suggest Malaysian-Chinese individuals in Malaysia who had greater intergroup contact opportunities (therefore less prone to biases) were less affected by race composition as compared to MalaysianChinese individuals in Australia who had fewer intergroup contact opportunities. However, without an actual measure of intergroup contact in the past, we are unsure whether Malaysian-Chinese in Australia formed favorable impressions of majority Malaysian-Malay individuals before or after arriving in Australia. In addition to intergroup contact opportunities, language used in the universities may be a factor explaining the differences between the two samples. In many public universities in Malaysia, Bahasa Melayu (the Malay language) is used as the main medium of instruction. Hence, Malaysian-Chinese who study in a public university in Malaysia tend to be proficient in the national language which then helps facilitate their understanding of the majority Malaysian-Malay's culture. In contrast, English is the main teaching medium in universities in Australia. English is also the day-to-day language used by Malaysian-Chinese students in Australia. Due to the lack of quality communication and understanding of Malay culture, Malaysian-Chinese in Australia might not have engaged in meaningful conversation with the out- 
group (Malaysian-Malays). Therefore, they might hold more prejudice toward the out-group members and are more affected by racial composition. Hence, future research should investigate past and current intergroup contact that the participants have had with out-group members, as well as the amount and quality of contact, as possible moderators.

Minority Malaysian-Chinese were the only racial group examined in this study. Future research should include majority Malaysian-Malay individuals. Studies have shown consistently that minority Black and Hispanic applicants were more attracted to organizations that featured minority representatives in recruitment advertising, whereas majority White applicants were unaffected by race composition (Avery 2003; Avery et al. 2004; Perkins et al. 2000; Wells 2008). It will be fruitful to examine if a similar pattern of results would be obtained from a non-Western society and whether a three-way interactive effect between race composition, participant race, and location on applicant attraction would be found. In addition to examining the interaction between participant race and location, we encourage further research to consider differences in the socioeconomic status of samples across locations. Only parents who are able to afford the high tuition fees of overseas universities send their children overseas. Hence, Malaysian-Chinese students in Australia are more likely to be from the middle- and upper-classes than MalaysianChinese students in Malaysia. Therefore, Malaysian-Chinese students in Australia might not experience pressure to land a job; they might be more selective in their job choice. In contrast, Malaysian-Chinese students in Malaysia often fight fiercely with the majority Malaysian-Malays for education and job opportunities due to the preferential treatment given to the majority group. Hence, MalaysianChinese in Malaysia may be less selective in their job decisions and less affected by race composition in an organization. This reasoning suggests an additional mediating mechanism in the form of job selectivity. We encourage future researchers to measure the employability of prospective job applicants to consider job selectivity as an explanation.

Finally, race was the only diversity dimension examined in the present study. The present study assumed that the applicants were using race as an important demographic attribute in their self-definitions. However, individuals have multiple social identities and tend to identify with groups that will enhance their self-identity (Tajfel and Turner 1986). For instance, people define themselves according to their racial groups as well as other social groups that are meaningful to them (e.g., a favorite football team). These social categories and self-categorizations may interact to affect an individual's evaluation of another person (van Bavel and Cunningham 2009). Individuals may use multiple social categories to form impressions of people, or emphasize a particular social category (e.g., race) while downplaying another (e.g., gender; Kulik et al. 2007). Hence, it is important to consider the simultaneous effect of multiple diversity dimensions on an individual's overall attraction to an organization. Further, future research should measure participants' identity salience and the degree of their racial identification. Applicants with high identification might be more strongly attracted to organizations featuring members of their own race than their counterparts who are low in identification (Linnehan et al. 2006).

\section{Conclusion}

In summary, the present study demonstrated two key findings. First, location moderated the relationship between race composition and applicant attraction. Minority Malaysian-Chinese participants in a location that offers many intergroup interaction opportunities were less affected by race composition than minority Malaysian-Chinese participants in a location that offers few intergroup interaction opportunities. Second, the extent to which participants perceived themselves as similar to the representatives (in terms of underlying values and attitudes) mediated the moderating relationship. Hence, organizations that want to achieve a diverse workforce should signal to minority applicants, particularly to those who are in a location that offers few opportunities for intergroup contact, that they value minority employees. It is beneficial for organizations to include minority representatives in their recruiting materials and foster perceptions of deep-level similarity (e.g., values) between applicants and the organization's representatives or the organization as a whole. 


\section{Appendix: 50\% Malay-50\% Chinese condition}

\section{Soroton Inc.}

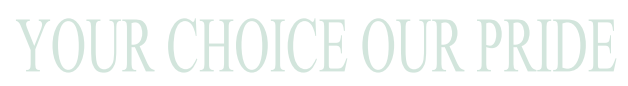

YOUR CHOICE OUR PRIDE

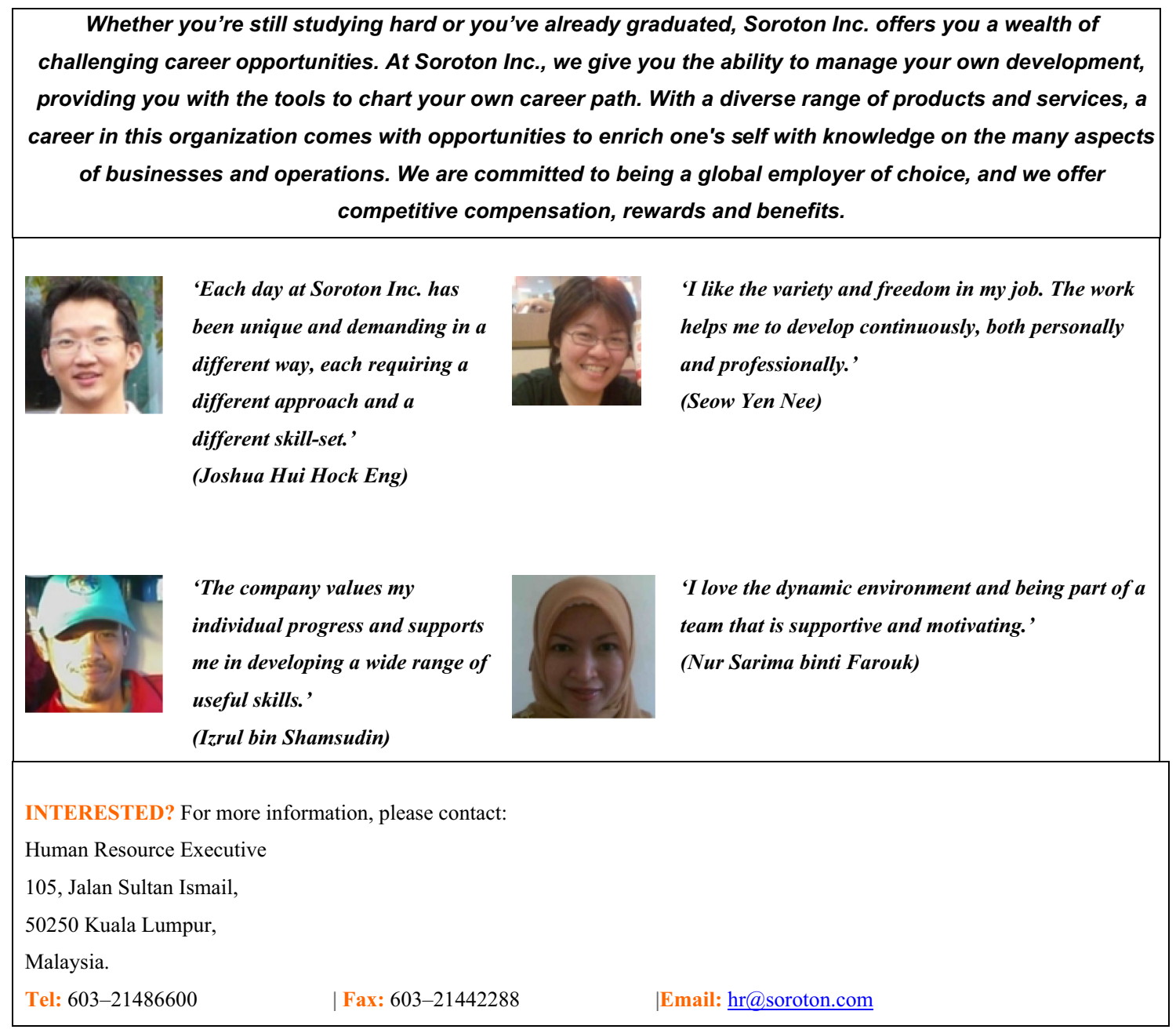

\section{References}

Abdul Khalid, M. (2011). NEP to NEM: Who cares? Wealth distribution in Malaysia. Persidangan Kebangsaan Ekonomi Malaysia ke VI (PERKEM VI) (pp. 400-409), June 2011.

Agadjanian, V., \& Liew, H. P. (2005). Preferential policies and ethnic differences in post-secondary education in Peninsular Malaysia. Race Ethnicity and Education, 8, 213-230. doi:10.1080/ 13613320500110659.
Allen, D. G., Mahto, R. V., \& Otondo, R. F. (2007). Web-based recruitment: Effects of information, organizational brand, and attitudes toward a web site on applicant attraction. Journal of Applied Psychology, 92, 1696-1708. doi:10.1037/0021-9010.92. 6.1696.

Allport, G. W. (1954). The nature of prejudice. Reading, MA: Addison-Wesley.

Anastasio, P., Bachman, B., Gaertner, S., \& Dovidio, J. (1997). Categorization, recategorization and common ingroup identity. 
In R. Spears, P. J. Oakes, N. Ellemers, \& S. A. Haslam (Eds.), The social psychology of stereotyping and group life (pp. 236-256). Malden, MA: Blackwell Publishing.

Ancheh, K. S. B. (2005). Factors influencing students' choice of Malaysian private higher education institutions. Unpublished doctoral thesis. Adelaide, SA: University of South Australia.

Ashforth, B. E., \& Mael, F. (1989). Social identity theory and the organization. Academy of Management Review, 14(1), 20-39. doi:10.5465/AMR.1989.4278999.

Avery, D. R. (2003). Reactions to diversity in recruitment advertising: Are differences black and white? Journal of Applied Psychology, 88, 672-679. doi:10.1037/0021-9010.88.4.672.

Avery, D. R., Hernandez, M., \& Hebl, M. R. (2004). Who's watching the race? Racial salience in recruitment advertising. Journal of Applied Social Psychology, 34, 146-161. doi:10.1111/j.15591816.2004.tb02541.x.

Avery, D. R., \& Thomas, K. M. (2004). Blending content and contact: the roles of diversity curriculum and campus heterogeneity in fostering diversity management competency. Academy of Management Learning \& Education, 3(4), 380-396. doi:10.5465/ AMLE.2004.15112544.

Barber, A. E. (1998). Recruiting employees: Individual and organizational perspectives. Thousand Oaks, CA: Sage.

Baskett, G. D. (1973). Interview decisions as determined by competency and attitude similarity. Journal of Applied Psychology, 57(3), 343-345. doi:10.1037/h0034707.

Bernama. (2012). Jobseekers must keep an open mind. Retrieved November 3, 2012 from http://www.freemalaysiatoday.com/ category/nation/2012/11/03/jobseekers-must-keep-an-open$\operatorname{mind} /$.

Biernat, M. (1990). Stereotypes on campus: How contact and liking influence perceptions of group distinctiveness. Journal of Applied Social Psychology, 20(18, Pt 2), 1485-1513. doi:10. 1111/j.1559-1816.1990.tb01489.x.

Brewer, M. B. (1979). In-group bias in the minimal intergroup situation: A cognitive-motivational analysis. Psychological Bulletin, 86, 307-324. doi:10.1037/0033-2909.86.2.307.

Brewer, M. B., \& Miller, N. (Eds.). (1984). Beyond the contact hypothesis: Theoretical perspectives on desegregation. Orlando, FL: Academic Press.

Brown, R., Eller, A., Leeds, S., \& Stace, K. (2007). Intergroup contact and intergroup attitudes: A longitudinal study. European Journal of Social Psychology, 37(4), 692-703. doi:10.1002/ejsp.384.

Brown, R., \& Turner, J. (1981). Interpersonal and intergroup behaviour. In J. Turner \& H. Giles (Eds.), Intergroup behaviour (pp. 33-65). Oxford, UK: Blackwell.

Byrne, D. (1971). The attraction paradigm. New York: Academic Press.

Byrne, D., \& Clore, G. L. (1970). A reinforcement model of evaluative responses. Personality: An International Journal, 1(2), 103-128.

Cable, D. M., \& Graham, M. E. (2000). The determinants of job seekers' reputation perceptions. Journal of Organizational Behavior, 21, 929-947. doi:10.1002/1099-1379(200012)21:8.

Cable, D. M., \& Judge, T. A. (1996). Person-organization fit, job choice decisions, and organizational entry. Organizational Behavior and Human Decision Processes, 67(3), 294-311.

Carless, S. A. (2005). The influence of fit perceptions, equal opportunity policies, and social support network on pre-entry police officer career commitment and intentions to remain. Journal of Criminal Justice, 33(4), 341-352. doi:10.1016/j. jcrimjus.2005.04.004.

Carless, S. A., \& Imber, A. (2007). The influence of perceived interviewer and job and organizational characteristics on applicant attraction and job choice intentions: The role of applicant anxiety. International Journal of Selection and Assessment, 15(4), 359-371. doi:10.1111/j.1468-2389.2007.00395.x.

Casper, W. J., Wayne, J. H., \& Manegold, J. G. (2013). Who will we recruit? Targeting deep-and surface-level diversity with human resource policy advertising. Human Resource Management, 52(3), 311-332.

Chapman, D. S., Uggerslev, K. L., Carroll, S. A., Piasentin, K. A., \& Jones, D. A. (2005). Applicant attraction to organizations and job choice: a meta-analytic review of the correlates of recruiting outcomes. Journal of Applied Psychology, 90(5), 928-944. doi:10.1037/0021-9010.90.5.928.

Chattopadhyay, P., Tluchowska, M., \& George, E. (2004). Identifying the in-group: A closer look at the influence of demographic dissimilarity on employee social identity. Academy of Management Review, 29, 180-202. doi:10.5465/AMR.2004.12736071.

Cook, S. W. (1978). Interpersonal and attitudinal outcomes in cooperating interracial groups. Journal of Research \& Development in Education, 12(1), 97-113.

Cox, T, Jr. (2001). Creating the multicultural organization: A strategy for capturing the power of diversity. Business school management series. Michigan: University of Michigan.

Crampton, S. M., \& Wagner, J. A. (1994). Percept-percept inflation in microorganizational research: An investigation of prevalence and effect. Journal of Applied Psychology, 79(1), 67-76. doi:10. 1037//0021-9010.79.1.67.

Cunningham, G. B. (2007). Perceptions as reality: The influence of actual and perceived demographic dissimilarity. Journal of Business Psychology, 22, 79-89. doi:10.1007/s10869-007-9052y.

Department of Statistics Malaysia. (2010). Population and demography: Population distribution and basic demographic characteristics. Retrieved October 20, 2011 from http://www.statistics. gov.my/portal/download_Population/files/census2010/Taburan_ Penduduk_dan_Ciri-ciri_Asas_Demografi.pdf.

Dovidio, J. F., Gaertner, S. L., \& Kawakami, K. (2003). Intergroup contact: The past, present, and the future. Group Processes \& Intergroup Relations, 6(1), 5-21. doi:10.1177/136843020300 6001009.

Elsass, P. M., \& Graves, L. M. (1997). Demographic diversity in decision-making groups: The experiences of women and people of color. Academy of Management Review, 22(4), 946-973. doi:10.5465/AMR.1997.9711022111.

Ferris, G. R., Judge, T. A., Rowland, K. M., \& Fitzgibbons, D. E. (1994). Subordinate influence and the performance evaluation process: Test of a model. Organizational Behavior and Human Decision Processes, 58(1), 101-135.

Gaertner, S. L., \& Dovidio, J. F. (2000). Reducing intergroup bias: The common ingroup identity model. Philadelphia, PA: Psychology Press.

Gaertner, S. L., Dovidio, J. F., Anastasio, P. A., Bachman, B. A., \& Rust, M. C. (1993). The common ingroup identity model: Recategorization and the reduction of intergroup bias. European Review of Social Psychology, 4(1), 1-26.

Gaertner, S. L., Rust, M. C., Dovidio, J. F., Bachman, B. A., \& Anastasio, P. A. (1994). The contact hypothesis: The role of a common ingroup identity on reducing intergroup bias. Small Group Research, 25(2), 224-249. doi:10.1177/104649649425 2005.

Gaertner, S. L., Rust, M. C., Dovidio, J. F., Bachman, B. A., \& Anastasio, P. A. (1996). The contact hypothesis: The role of a common ingroup identity on reducing intergroup bias among majority and minority group members. In J. L. Nye \& A. M. Brower (Eds.), What's social about social cognition? Research on socially shared cognition in small groups (pp. 230-260). Thousand Oaks, CA: SAGE Publications. 
Goldberg, C. B. (2005). Relational demography and similarityattraction in interview assessments and subsequent offer decisions: Are we missing something? Group Organization Management, 30, 597-624. doi:10.1177/1059601104267661.

Gottfredson, N. C., Panter, A. T., Daye, C. E., Allen, W. A., Wightman, L. F., \& Deo, M. E. (2008). Does diversity at undergraduate institutions influence student outcomes? Journal of Diversity in Higher Education, 1(2), 80-94. doi:10.1037/ 1938-8926.1.2.80.

Graves, L. M., \& Powell, G. N. (1995). The effect of sex similarity on recruiters' evaluations of actual applicants: A test of the similarity-attraction paradigm. Personnel Psychology, 48(1), 85-98. doi:10.1111/j.1744-6570.1995.tb01747.x.

Harrison, D. A., Price, K. H., \& Bell, M. P. (1998). Beyond relational demography: Time and the effects of surface- and deep-level diversity on work group cohesion. Academy of Management Journal, 41(1), 96-107. doi:10.2307/256901.

Harrison, D. A., Price, K. H., Gavin, J., \& Florey, A. (2002). Time, teams, and task performance: Changing effects of surface- and deep-level diversity on group functioning. Academy of Management Journal, 45(5), 1029-1045. doi:10.2307/3069328.

Hayes, A. F., \& Preacher, K. J. (2014). Statistical mediation analysis with a multicategorical independent variable. British Journal of Mathematical and Statistical Psychology, 67, 451-470. doi:10. 1111/bmsp.12028.

Highhouse, S., Lievens, F., \& Sinar, E. F. (2003). Measuring attraction to organizations. Educational and Psychological Measurement, 63(6), 986-1001. doi:10.1177/0013164403258403.

Hogg, M. A., \& Terry, D. J. (2000). Social identity and selfcategorization processes in organizational contexts. Academy of Management Review, 25(1), 121-140. doi:10.5465/AMR.2000. 2791606.

Johns, G. (2006). The essential impact of context on organizational behavior. Academy of Management Review, 31(2), 386-408. doi:10.5465/AMR.2006.20208687.

Kanter, R. M. (1977). Men and women of the corporation. New York: Basic Books

Kraichy, D., \& Chapman, D. S. (2014). Tailoring Web-Based Recruiting Messages: Individual Differences in the Persuasiveness of Affective and Cognitive Messages. Journal of Business and Psychology, 29(2), 253-268.

Kramer, R. M. (1991). Intergroup relations and organizational dilemmas: The role of categorization processes. Research in Organizational Behavior, 13, 191-228.

Kulik, C. T., Roberson, L., \& Perry, E. L. (2007). The multiplecategory problem: Category activation and inhibition in the hiring process. Academy of Management Review, 32(2), 529-548. doi:10.5465/AMR.2007.24351855.

Li, J., Karakowsky, L., \& Siegel, J. P. (1999). The effects of proportional representation on intragroup behavior in mixed-race decision-making groups. Small Group Research, 30(3), 259-279. doi: $10.1177 / 104649649903000301$.

Linnehan, F., Chrobot-Mason, D., \& Konrad, A. M. (2006). Diversity attitudes and norms: The role of ethnic identity and relational demography. Journal of Organizational Behaviour, 27(4), 419-442. doi:10.1002/job.382.

Nakamura, R. (2012). Malaysia, a racialized nation: Study of the concept of race in Malaysia. Paper presented at International Proceedings of Economics Development and Research: Knowledge, Culture and Society, 42, 134-142.

Pak, J. (2013). Is Malaysia university entry a level playing field? Retrieved from http://www.bbc.com/news/world-asia-23841888.

Pelled, L. H. (1996). Demographic diversity, conflict, and work group outcomes: An intervening process theory. Organization Science, $7(6), 615-631$.
Perkins, L. A., Thomas, K. M., \& Taylor, G. A. (2000). Advertising and recruitment: Marketing to minorities. Psychology \& Marketing, 17, 235-255. doi:10.1002/(SICI)1520-6793(200003)17:3.

Pettigrew, T. F. (1971). Racially separate or together?. New York: McGraw-Hill.

Pettigrew, T. F. (1998). Intergroup contact theory. Annual Review of Psychology, 49, 65-85. doi:10.1146/annurev.psych.49.1.65.

Pettigrew, T. F., \& Tropp, L. R. (2006). A meta-analytic test of intergroup contact theory. Journal of Personality and Social Psychology, 90(5), 751-783. doi:10.1037/0022-3514.90.5.751.

Pettigrew, T. F., \& Tropp, L. R. (2008). How does intergroup contact reduce prejudice? Meta-analytic tests of three mediators. European Journal of Social Psychology, 38(6), 922-934. doi:10. 1002/ejsp.504.

Plumer, B. (2013). These ten charts show the black-white economic gap hasn't budged in 50 years. Retrieved from http://www. washingtonpost.com/blogs/wonkblog/wp/2013/08/28/theseseven-charts-show-the-black-white-economic-gap-hasnt-budgedin-50-years.

Podsakoff, P. M., MacKenzie, S. B., Lee, J. Y., \& Podsakoff, N. P. (2003). Common method biases in behavioral research: a critical review of the literature and recommended remedies. Journal of Applied Psychology, 88(5), 879-903. doi:10.1037/0021-9010.88. 5.879 .

Podsakoff, P. M., \& Organ, D. W. (1986). Self-reports in organizational research: Problems and prospects. Journal of Management, 12(4), 531-544. doi:10.1177/014920638601200408.

Pratto, F., Liu, J. H., Levin, S., Sidanius, J., Shih, M., Bachrach, H., \& Hegarty, P. (2000). Social dominance orientation and the legitimization of inequality across cultures. Journal of CrossCultural Psychology, 31, 369-409. doi:10.1177/00220221000 31003005 .

Richard, O. C. (2000). Racial diversity, business strategy, and firm performance: A resource-based view. Academy of Management Journal, 43, 164-177. doi:10.2307/1556374.

Riordan, C. M. (2000). Relational demography within groups: Past developments, contradictions, and new directions. In G. R. Ferris (Ed.), Research in personnel and human resources management (pp. 131-173). Greenwich, CT: JAI Press.

Rynes, S. L. (1991). Recruitment, job choice, and post-hire consequences: A call for new directions. In M. D. Dunnette \& L. M. Hough (Eds.), Handbook of industrial and organizational psychology (pp. 399-444). Palo Alto, CA: Consulting Psychologists Press.

Sackett, P. R., \& Larson, J. R, Jr. (1990). Research strategies and tactics in industrial and organizational psychology. In $\mathrm{M}$. D. Dunnette \& L. M. Hough (Eds.), Handbook of industrial and organizational psychology (pp. 419-489). Palo Alto, CA: Consulting Psychologists Press.

Schneider, B. (1987). The people make the place. Personnel Psychology, 40(3), 437-453. doi:10.1111/j.1744-6570.1987. tb00609.x.

Shrivastava, S., \& Gregory, J. (2009). Exploring the antecedents of perceived diversity. Journal of Management \& Organization, 15(4), 526-542. doi:10.5172/jmo.15.4.526.

Smedley, B. D., Butler, A. S., \& Bristow, L. R. (Eds.). (2004). In the nation's compelling interest: Ensuring diversity in the health care workforce. Washington, DC: The National Academies Press.

Spence, M. (1973). Job market signaling. Quarterly Journal of Economics, 87(3), 355-374. doi:10.2307/1882010.

Tajfel, H., \& Turner, J. C. (1986). The social identity theory of intergroup behavior. In S. Worchel \& W. G. Austin (Eds.), Psychology of intergroup relations (pp. 7-24). Chicago: NelsonHall. 
Tan, A. M. (2002). Malaysian private higher education: Globalization, privatization, transformation and marketplaces. London, UK: Asean Academic Press.

Tan, E. \& Sharma, Y. (2013). Uproar over 'race bias' in public university places. University World News, 281. Retrieved from http://www.universityworldnews.com/article.php?story=201307 17110401762

The Economist. (2005). Race in Malaysia: Failing to spread the wealth. Retrieved January 3, 2013 from http://www.economist. com/node/4323219?Story_ID=E1_QPNPNTJ.

Tsui, A. S., Egan, T. D., \& O'Reilly, C. A. (1992). Being different: Relational demography and organizational attachment. Administrative Science Quarterly, 37, 549-579. doi:10.5465/AMBPP. 1991.4976867.

Tsui, A. S., \& O'Reilly, C. A. I. I. I. (1989). Beyond simple demographic effects: The importance of relational demography in superior-subordinate dyads. Academy of Management Journal, 32(2), 402-423. doi:10.2307/256368.

Turban, D. B., \& Jones, A. P. (1988). Supervisor-subordinate similarities: Types, effects, and mechanisms. Journal of Applied Psychology, 73, 228-234. doi:10.1037/0021-9010.73.2.228.

Turner, J. C. (1985). Social categorization and the self-concept: A social cognitive theory of group behavior. Advances in group processes: Theory and research, 2, 77-121.

Turner, J. C. (1987). Rediscovering the social group: A selfcategorization theory. Oxford: Blackwell Publishers.

van Bavel, J. J., \& Cunningham, W. A. (2009). Self-categorization with a novel mixed-race group moderates automatic social and racial biases. Personality and Social Psychology Bulletin, 35(3), 321-335. doi:10.1177/0146167208327743.

Wanous, J. P., Reichers, A. E., \& Hudy, M. J. (1997). Overall job satisfaction: How good are single-item measures? Journal of Applied Psychology, 82(2), 247-252. doi:10.1037/0021-9010.82. 2.247 .

WealthInequality.org. (2015). Immigrants and wealth. Retrieved from http://wealthinequality.org/Immigrants_and_Wealth.html.

Wells, C. L., IV. (2008). The relationship between potential job applicants' ethnic identity and their attraction to organizations as a function of the racial diversity depicted in recruitment brochures. Unpublished master thesis, Wayne State University, Detroit, Michigan.

Williams, R. M, Jr. (1947). The reduction of intergroup tensions: A survey of research on problems of ethnic, racial, and religious group relations. New York: Social Science Research Council.

Wolsko, C., Park, B., Judd, C. M., \& Bachelor, J. (2003). Intergroup contact: Effects on group evaluations and perceived variability. Group Processes \& Intergroup Relations, 6(1), 93-110. doi:10. $1177 / 1368430203006001014$.

Zellmer-Bruhn, M. E., Maloney, M. M., Bhappu, A. D., \& Salvador, R. (2008). When and how do differences matter? An exploration of perceived similarity in teams. Organizational Behavior and Human Decision Processes, 107(1), 41-59. doi:10.1016/j.obhdp. 2008.01.004. 